\title{
Performance of recycled ceramic waste as aggregates in hot mix asphalt mixtures
}

\begin{abstract}
Ceramic waste materials are abundantly available in Malaysia from the production of ceramic tiles. In general, ceramic materials seem to possess low thermal conductivity characteristics that could reduce pavement temperatures when used as aggregates in asphalt mixtures. A study was undertaken to look into the performance of crushed ceramics incorporated in asphalt mixtures to replace the conventional granite aggregates from sizes $5.0 \mathrm{~mm}$ down including the 75 micron filler. The replacement was done proportionally with $0 \%, 20 \%, 40 \%, 60 \%, 80 \%$ and $100 \%$ ceramic aggregates by weight of granite. Several mix designs with various percentages of ceramic aggregates were formulated to determine the marshal properties such as stability, flow, and resilient modulus. In addition, the potential of ceramic aggregates in reducing the asphalt pavement temperatures was also studied. The outcome of the study showed that the ceramic aggregates in the asphalt mixtures were able to improve the performance of the mixture up to $20 \%$ which means there is a great potential for the use of it in road construction. Besides that, the rate of heating $(\mathrm{RoH})$ compacted samples subjected to various temperatures dropped significantly as compared with the control granite specimens. The fatigue performance of the compacted and temperature conditioned ceramic asphalt mixtures displayed an interesting trend in terms of strain resistance at elevated temperatures.
\end{abstract}

Keyword: Ceramic waste aggregate; Asphalt; Stability; Resilient modulus 